\title{
Photocatalytic Dye Degradation and Biological Activities of Cu-Doped ZnSe Nanoparticles and Their Insights
}

\author{
V. Beena ${ }^{1}$, S. L. Rayar ${ }^{2}$, S. Ajitha ${ }^{1}$, Awais Ahmad ${ }^{3, * \mathbb{D}}$, Faiza Jan Iftikhar ${ }^{4}$, Khamael M. Abualnaja ${ }^{5}$, \\ Taghrid S. Alomar ${ }^{6, *}$, Mohmed Ouladsmne ${ }^{7}$ (D) and Shafaqat Ali ${ }^{8,9, *(D)}$
}

1 Department of Physics, Nanjil Catholic College of Arts and Science, Manonmaniam Sundaranar University, Kanyakumari 629153, India; drbeenaphysics@gmail.com (V.B.); ajithaphyholy@gmail.com (S.A.)

2 Department of Physics, St. Judes College, Kanyakumari 629176, India; drslrayar@gmail.com

3 Departamento de Quimica Organica, Universidad de Cordoba, Edificio Marie Curie (C-3), Ctra Nnal IV-A, Km 396, E14014 Cordoba, Spain

4 School of Applied Sciences \& Humanity, NUSASH, National University of Technology, Islamabad 42000, Pakistan; faizajiftikhar@nutech.edu.pk

5 Department of Chemistry, College of Science, Taif University, Taif 21944, Saudi Arabia; k.ala@tu.edu.sa

6 Department of Chemistry, College of Science, Princess Nourah bint Abdulrahman University, Riyadh 11671, Saudi Arabia

7 Advanced Materials Research Chair, Chemistry Department, College of Science, King Saud University, Riyadh 11451, Saudi Arabia; mouladsmane@ksu.edu.sa

8 Department of Environmental Sciences and Engineering, Government College University Faisalabad, Faisalabad 38000, Pakistan

9 Department of Biological Sciences and Technology, China Medical University, Taichung 40402, Taiwan

check for

updates

Citation: Beena, V.; Rayar, S.L.; Ajitha, S.; Ahmad, A.; Iftikhar, F.J.; Abualnaja, K.M.; Alomar, T.S.; Ouladsmne, M.; Ali, S. Photocatalytic Dye Degradation and Biological Activities of Cu-Doped ZnSe Nanoparticles and Their Insights. Water 2021, 13, 2561. https:// doi.org/10.3390/w13182561

Academic Editor: Stefanos Giannakis

Received: 18 August 2021

Accepted: 7 September 2021

Published: 17 September 2021

Publisher's Note: MDPI stays neutral with regard to jurisdictional claims in published maps and institutional affiliations.

Copyright: (c) 2021 by the authors. Licensee MDPI, Basel, Switzerland. This article is an open access article distributed under the terms and conditions of the Creative Commons Attribution (CC BY) license (https:// creativecommons.org/licenses/by/ $4.0 /)$.
* Correspondence: awaisahmed@gcuf.edu.pk (A.A.); tsalmoar@pnu.edu.sa (T.S.A.); shafaqataligill@yahoo.com (S.A.)

\begin{abstract}
Environmental nanotechnology has received much attention owing to its implications on environmental ecosystem, and thus is promising for the elimination of toxic elements from the aquatic surface. This work focuses on $\mathrm{Cu}$-doped $\mathrm{ZnSe}$ nanoparticles using the co-precipitation method. The synthesized $\mathrm{Cu}$-doped $\mathrm{ZnSe}$ nanoparticles were examined for structural, optical, and morphological properties with the help of XRD, FTIR, UV/vis diffuse reflection spectroscopy (DRS), FESEM, TEM, and XPS. The synthesized $\mathrm{Cu}$-doped $\mathrm{ZnSe}$ nanoparticles revealed the presence of $\mathrm{Cu}^{2+}$ in the $\mathrm{ZnSe}$ lattice, which has been shown to take a predominant role for enhanced catalysis in the Cu-doped ZnSe nanoparticles. The synthesized $\mathrm{Cu}$-doped $\mathrm{ZnSe}$ nanoparticles were investigated for their catalytic and antibacterial activities. The $0.1 \mathrm{M}$ copper-doped ZnSe nanoparticles exhibited the highest rate of degradation against the methyl orange dye, which was found to be $87 \%$. A pseudo-first-order kinetics was followed by Cu-doped ZnSe nanoparticles with a rate constant of $0.1334 \mathrm{~min}^{-1}$. The gram-positive and gram-negative bacteria were used for investigating the anti-bacterial activity of the $\mathrm{Cu}$-doped ZnSe nanoparticles. The $\mathrm{Cu}$-doped $\mathrm{ZnSe}$ nanoparticles exhibited enhanced photocatalytic and antibacterial activity.
\end{abstract}

Keywords: Cu-doped ZnSe NPs; MO; photocatalysis; visible light

\section{Introduction}

For the removal of dyes as organic contaminants in an aqueous system, conventional methods have been in vogue, which include ultrafiltration, reverse osmosis, ion exchange, adsorption, photocatalytic degradation, and so on; nevertheless, these methods cannot completely degrade the organic pollutants [1-7].

Researchers have taken an immense interest in employing nanoparticles for photocatalytic dye degradation. The photocatalytic degradation process [8,9] is a highly efficient oxidation method for decomposing organic contaminants. The electrons are excited and steered from the valence band to the conduction band of the photocatalyst using energy 
from an optical source, and highly reactive hydroxyl radicals are generated for oxidation and degradation of contaminants [10]. Thanks to their superior thermal stability, corrosion resistance, and high surface area to volume ratio, metal oxides like titanium oxide, zinc oxide, manganese oxide, and manganese dioxide have gained significant attention for photocatalysis [11]. These materials have been proven to be able to remove a wide spectrum of dyes from the aqueous solutions [12].

Photocatalytic degradation is the most promising technology for removing dyes, pigments, or colorants from aqueous media owing to its efficiency, cost-effectiveness, selectivity, and flexible operation modes. For this purpose $\mathrm{ZnSe}$, a intrinsic semiconductor that absorbs ultraviolet/visible light, has been investigated, having a bandgap of $2.7 \mathrm{eV}$ [13,14]. It is also a strong competitor to other materials for photocatalytic applications owing to its excellent energy band location. ZnSe-based nanostructures, such as $\mathrm{ZnO} / \mathrm{ZnSe}[13,15]$, $\mathrm{Bi}_{2} \mathrm{~S}_{3}$-ZnSe [14], and $\mathrm{FeSe}_{2} / \mathrm{ZnSe}[16,17]$, demonstrate improved photocatalytic performance. Similarly, it is reported that composited polymers act as an active support for nanoparticles for photocatalysis, providing mechanical strength and architectural diversity. PANI/ZnO nanocomposites have been reported for photocatalytic degradation of dyes malachite green and methylene blue under UV and natural sunlight irradiation with $99 \%$ efficiency. The presence of $\mathrm{Cu}$-doped $\mathrm{ZnSe}$ in the composite polymer films is confirmed by XPS, UV-Vis, and fluorescence studies by [18]. Similarly, different methods have been employed such as the wet chemical approach to successfully manufacture $\mathrm{ZnS}$ and metal $(\mathrm{Mn}, \mathrm{Cu}$ )-doped $\mathrm{ZnS}$. The chemical bonding and crystal structure have been examined using FTIR and X-ray diffraction [19]. Cu-doped ZnS nanoparticles were prepared using a co-precipitation technique and studied via $X$-ray diffraction (XRD), scanning electron microscopy (SEM), UV-vis absorption spectroscopy, and photoconductivity (PC) [20]. In the same vein, Ag-decorated $\mathrm{Cu}$-doped $\mathrm{ZnO}$ nanoparticles have been successfully fabricated and investigated through XRD and FTIR [21]. Cu-doped ZnO NPs have been used to degrade dyes in the UV-visible region more efficiently as compared with undoped $\mathrm{ZnO}$ NPs [22]. Photocatalytic activity of Cu-doped $\mathrm{ZnS}$ is found to be significantly higher under visible light as compared with UV light. The optimal concentration of $\mathrm{Cu}$-doped $\mathrm{ZnS}$ was observed to be $3 \mathrm{~mol} \%$ for photocatalytic applications [23]. The photocatalytic activity of $\mathrm{Cu}$-doped $\mathrm{ZnS}$ was probed by the hydrogen generation experiment using a solar simulator. The highest apparent quantum yield was $\sim 11 \%$ [24]. These copper-doped zinc-related materials have been shown to demonstrate the highest catalytic activity and morphological enhancement as compared with the pristine materials by enhancing the production of free radicals. In this present work, $\mathrm{Cu}$-doped $\mathrm{ZnSe}$ nanoparticles were synthesized from a simple co-precipitation method and their catalytic activity was examined by employing methyl orange (MO) dye in aqueous solution as a model dye and its rate of kinetics was investigated. The bacterial efficiency of the $\mathrm{Cu}$-doped $\mathrm{ZnSe}$ nanoparticles was examined by employing gram-positive (S. aureus) and gram-negative (E. coli) bacteria. The photocatalytic and bacterial efficiency of the $\mathrm{Cu}$-doped $\mathrm{ZnSe}$ nanoparticles prove it as a promising material for the removal of pollutants in water.

\section{Materials and Methods}

\subsection{Materials}

The synthesized materials were procured from HiMedia, Mumbai, India (99\% purity). The chemicals (copper nitrate, $\mathrm{CuNO}_{3}$ ), zinc acetate dihydrate $-\mathrm{C}_{4} \mathrm{H}_{6} \mathrm{O}_{4} \mathrm{Zn}_{2} \mathrm{H}_{2} \mathrm{O}$, 2mercaptoethanol $-\mathrm{C}_{2} \mathrm{H}_{6} \mathrm{OS}$, sodium borohydride $-\mathrm{NaBH}_{4}$, methyl orange dye$\mathrm{C}_{14} \mathrm{H}_{14} \mathrm{~N}_{3} \mathrm{NaO}_{3} \mathrm{~S}$, and sodium hydroxide- $\mathrm{NaOH}$ were used for further processing of $\mathrm{Cu}$-doped $\mathrm{ZnSe}$ nanoparticles. The solvent is a doubly distilled water.

\subsection{Synthesis Process}

The $\mathrm{Cu}$-doped $\mathrm{ZnSe}$ nanoparticles were synthesized by a two-step process. The first step is to dissolve $0.5 \mathrm{M}$ zinc acetate dehydrate solution in 2-mercaptoethanol and $0.01 \mathrm{M}$ copper nitrate solutions by continuously stirring with a magnetic stirrer. Subsequently, 
selenium powder $(0.5 \mathrm{M})$ was added with sodium hydroxide solution to obtain the sodium hydroxide selenide solution. The zinc and selenium solution was then heated to $100{ }^{\circ} \mathrm{C}$ while maintaining the $\mathrm{pH}$ at 10 with $\mathrm{NaOH}$. The reaction mixture was then allowed to stir for $24 \mathrm{~h}$ at $100{ }^{\circ} \mathrm{C}$. Thereafter, the obtained precipitate was washed with ethanol or distilled water followed by drying in vacuum for $48 \mathrm{~h}$ at $80^{\circ} \mathrm{C}$. Finally, the processed powdered sample was kept in an oven for $200^{\circ} \mathrm{C}$. The as prepared powder sample was then used for further measurements. The same method was used for synthesizing $0.05 \mathrm{M}, 0.01$, and $0.1 \mathrm{M}$ copper nitrate-doped $\mathrm{ZnSe}$ nanoparticles [25]. The synthesis process of $\mathrm{Cu}$-doped $\mathrm{ZnSe}$ nanoparticles is depicted in Scheme 1.

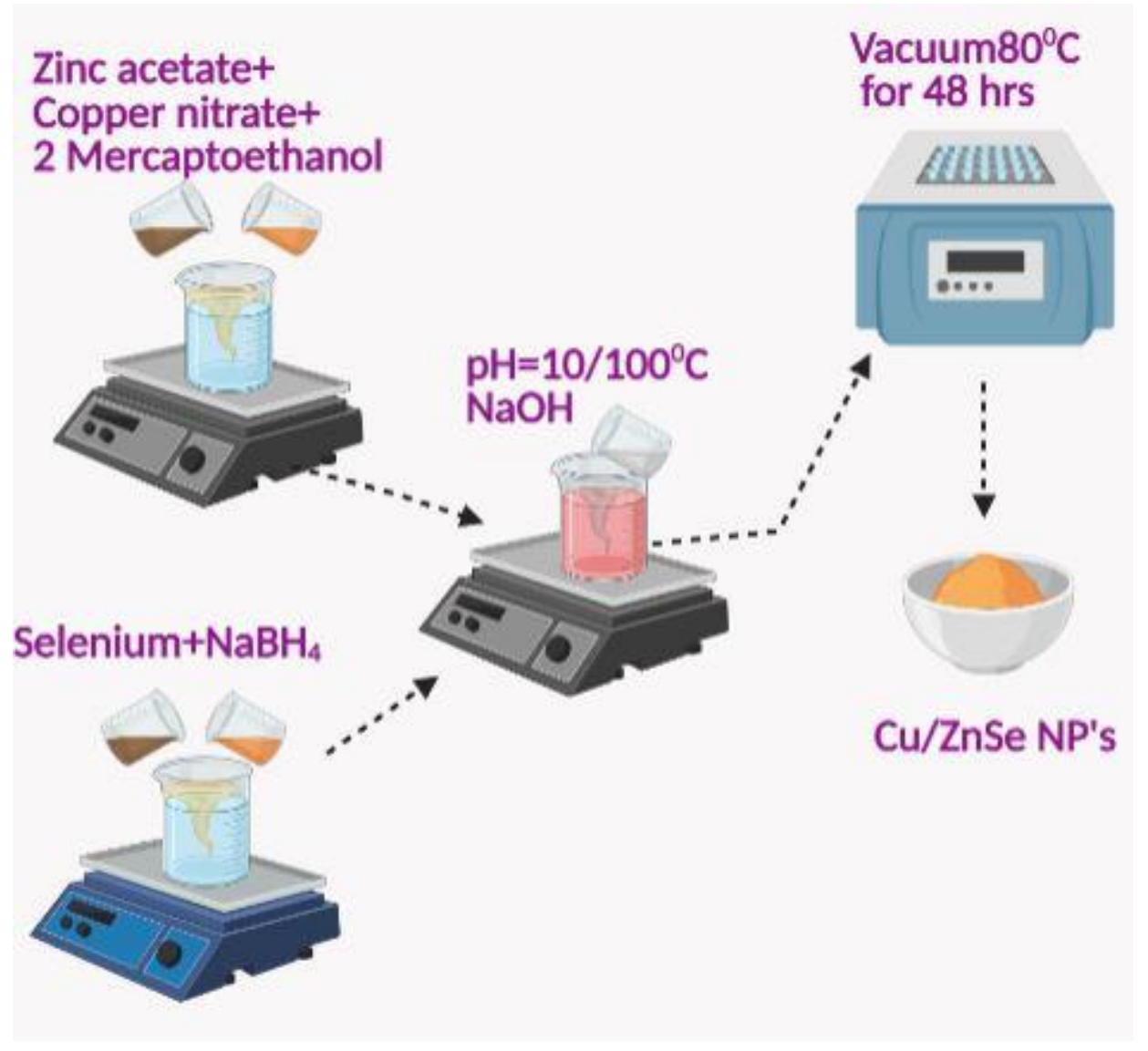

Scheme 1. Synthesis steps of the Cu-doped ZnSe nanoparticles.

\subsection{Characterization}

Crystal structure and the phase changes were probed using X-ray diffraction (PAnalytical X-ray diffractometer, $\mathrm{Cu}-\mathrm{K}_{\alpha}$ wavelength) (JDX-3532, JEOL, Tokyo, Japan). The optical identity was derived from UV/vis DRS (Shimadzu-2700 spectrophotometer). The surface functional groups were observed with an FT-IR spectrometer (Perkin Elmer) (IR Prestige 21, Shimadzu, Kyoto, Japan). The morphological changes were identified by employing FE-SEM with EDX (Sigma, Zeiss, Jena, Germany) and HR-TEM (JEOL-2100) (Sigma, Zeiss, Jena, Germany). Furthermore, the binding energy of the synthesized materials was studied by XPS (XPS, PHI 500, California, CA, USA).

\subsection{Antibacterial Activity}

The bacterial evaluation of the synthesized Cu-doped $\mathrm{ZnSe}$ nanoparticles was analyzed using gram-positive (S. aureus) and gram-negative (E. coli) bacteria. The disc diffusion method was used to find the efficiency of the nanoparticles. Mueller Hinton broth was used to grow the bacteria overnight. The grown bacteria were isolated $\left(100 \mu \mathrm{L} \times 10^{-7} \mathrm{CFU}\right)$ and streaked onto the sterilized agar Petri plates. A paper disc was inserted onto the Petri plates 
with a diameter of $6 \mathrm{~mm}$. The disc was loaded with various concentrations $(25 \mu \mathrm{L}, 50 \mu \mathrm{L}$, and $100 \mu \mathrm{L}$ ) of nanoparticles. The weighted discs were incubated for $24 \mathrm{~h}$ at $37^{\circ} \mathrm{C}$. The incubated discs were then probed for the zone of inhibition for the cultured bacteria. The zone shows prominent bacterial destruction, where the range of the zone was measured in $\mathrm{mm}$ scale [25]. The same experiment conditions were triplicated for accuracy.

\subsection{Photocatalytic Dye Degradation}

The photocatalytic dye degradation of MO dye was investigated by employing Cudoped ZnSe nanoparticles. The light source used for the experiment is a Xenon lamp that gives off visible light. The catalyst $(10 \mathrm{mg})$ was dissolved in $100 \mathrm{~mL}$ of the dye solution and placed in dark conditions for $30 \mathrm{~min}$. The dark condition helped to achieve the adsorption desorption equilibrium. Then, visible light was irradiated on the sample and, after a certain time interval, an aliquot of $3 \mathrm{~mL}$ from the solution was taken out and centrifuged at $5000 \mathrm{rpm}$ to remove the nanoparticles to determine the dye degradation accuracy. The collected samples were recorded in a UV/vis spectrometer. The dye degradation efficiency was calculated using Equation (1) as follows:

$$
\text { Degradationefficiency }(\%)=\frac{C_{0-C}}{C_{0}} \times 100
$$

where $C_{0}$ denotes initial dye concentration without light and $C$ is the light exposed dye concentration.

\section{Results and Discussion}

\subsection{XRD Analysis}

The XRD pattern of copper-doped ZnSe nanoparticles is shown in Figure 1. The copper peaks are indexed at $2 \theta=43.8^{\circ}, 50.7^{\circ}$, and $74.3^{\circ}$, corresponding to (111), (200), and (220) miller planes, respectively. Their patterns are well-matched with the std. JCPDS card no. of 04-0836 with an FCC (face-centered cubic) structure $[25,26]$. The copper modifies the ZnSe nanoparticles, as shown in Figure 1. The ZnSe nanoparticles' peaks were observed at $2 \theta=27.3^{\circ}, 45.3^{\circ}, 53.7^{\circ}, 66^{\circ}$, and $73^{\circ}$ for (111), (220), (311), (400), and (203) planes, respectively. The distinct peaks of copper as introduced into the ZnSe nanoparticles by doping have marginally changed the nature of the ZnSe nanoparticles. By introducing copper into $\mathrm{ZnSe}$, the cubic structure is modified with respect to the size and growth of orientation of the NP, which converts copper to $\mathrm{Cu}$ (II) phase. The $\mathrm{Cu}$ (II) phase is confirmed by the narrow $\mathrm{XRD}$ peaks at $31.7^{\circ}$. The $\mathrm{Cu}$ (II) phase was reassured by the XPS technique. The pristine $\mathrm{ZnSe}$ nanoparticles are reoriented by the addition of copper into the crystal system. The copper-doped ZnSe nanoparticles' size was determined by the Debye-Sherrer equation. The calculated values are $18<24<31 \mathrm{~nm}$ for $0.01<0.05<0.1 \mathrm{M}$ copper-doped into the ZnSe nanoparticles, respectively [27].

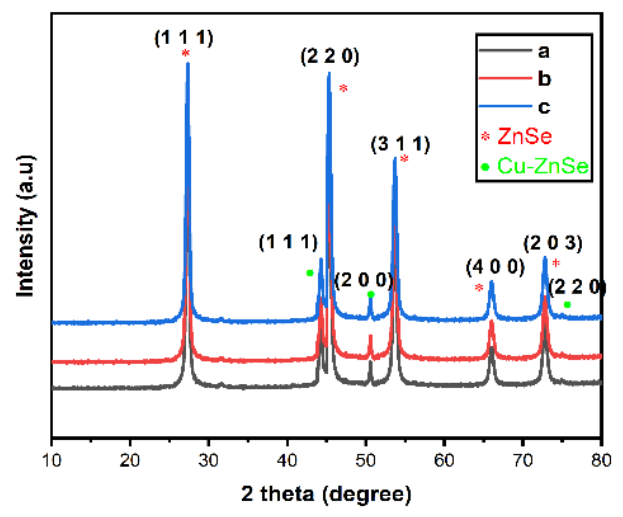

Figure 1. X-ray diffraction patterns of $\mathrm{Cu}(0.01,0.05$, and $0.1 \mathrm{M})$-doped $\mathrm{ZnSe}$ nanoparticles. 


\subsection{FTIR Analysis}

The synthesized sample purity and surface modification of ZnSe nanoparticles doped with different $\mathrm{Cu}$ concentrations were evaluated by FTIR spectrum, as depicted in Figure 2 . The different concentrations of $\mathrm{Cu}^{2+}$ cations in ZnSe nanoparticles demonstrate different kinds of bond stretching and vibrations, as seen in the spectrum. Sample a contains a low intensity $\mathrm{OH}$ stretching bond. However, sample $\mathrm{b}$ and $\mathrm{c}$ show high intensity of the bond and a broad spectrum of $\mathrm{OH}$ stretching at $\sim 3500 \mathrm{~cm}^{-1}$ is observed. The peaks at 1593,1622 , and $1640 \mathrm{~cm}^{-1}$ indicate the interaction between the $\mathrm{Cu}^{2+}, \mathrm{Zn}^{2+}$, and $\mathrm{Se}^{2-}$ of the carboxylic acid group [28]. Bond frequencies at 1246, 1321, and $1305 \mathrm{~cm}^{-1}$ are responsible for the stretching vibration of the C-O group [29]. The peak intensities gradually increase when $\mathrm{Cu}^{2+}$ cation concentration increased, boosting the interaction with the $\mathrm{ZnSe}$ nanoparticles. The increased peak values denote the reformation of the ZnSe nanoparticles when doped with $\mathrm{Cu}$. The peaks at 488,461 , and $487 \mathrm{~cm}^{-1}$ are attributed to the presence of $\mathrm{Zn}$-Se stretching vibrations, while those at $944,940,836,834,826,720,698,692,552$, and $520 \mathrm{~cm}^{-1}$ correspond to the formation of $\mathrm{Cu}-\mathrm{Zn}-\mathrm{Se}$ by reduction of $\mathrm{Cu}^{2+}[30]$. The obtained peaks strongly indicate surface re-orientation of ZnSe nanoparticles and reduction of $\mathrm{Cu}^{2+}$ and ZnSe nanoparticles [31]. The surface was strongly modified with the $\mathrm{Cu}$ addition/doping of the ZnSe nanoparticle in sample c. Sample c has a high-level interaction between the reactants and nano reduction of the synthesized samples occurred.

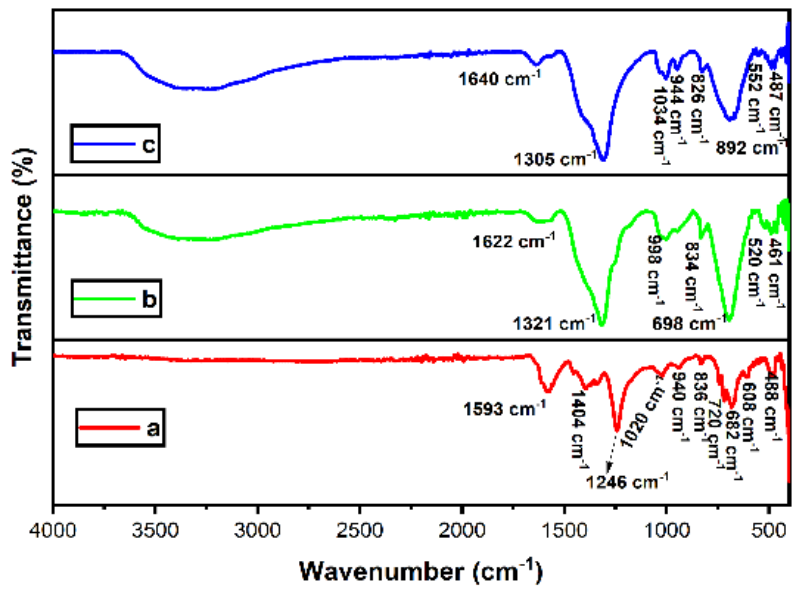

Figure 2. FT-IR spectra of ZnSe NPs doped with (a) $0.01 \mathrm{M} \mathrm{Cu}$, (b) $0.05 \mathrm{Cu}$, and (c) $0.1 \mathrm{M} \mathrm{Cu}$.

\subsection{UV-DRS Analysis}

Figure 3a,b shows the synthesized Cu-doped ZnSe absorption and bandgap energy as measured by UV/DRS spectroscopy. The undoped ZnSe nanoparticles show an absorption edge at $390 \mathrm{~nm}$. However, when $\mathrm{Cu}$ was added to the systems, the adsorption edge shifted towards the lower wavelength side at $245 \mathrm{~nm}$ and broad-spectrum (shoulder peaks at $650 \mathrm{~nm})$ in the visible region [31]. The $\mathrm{Cu}^{2+}$ ions to $\left(\mathrm{Zn}^{2+} \mathrm{Se}^{2-}\right) \mathrm{ZnSe}$ create more active sites at the surface. The blueshift occurred as a result of the introduction of the $\mathrm{Cu}^{2+}$ ions. The transfer of charge $\mathrm{Cu}^{2+} / \mathrm{Zn}^{2+} \rightarrow \mathrm{Se}^{2-}$ has been shown to increase the optical behaviour. The interaction between copper, zinc, and selenium shifted the optical tendency to the lower side of the wavelength. In this case, the optical band gap is determined by the Kubelka-Munk theory. The calculated band gap values are $2.65 \mathrm{eV}, 2.43 \mathrm{eV}$, and $2.06 \mathrm{eV}[25,32]$. The narrow bandgap represents photocatalytic activity in the range of visible light. The energy gap between the pure $\mathrm{ZnSe}$ and doped $\mathrm{ZnSe}$ nanoparticle is $\Delta \mathrm{Eg}=0.71 \mathrm{eV}$, which is redshifted. The decreased bandgap confirmed the formation of the active sites [33]. The penetration/scattering ability is the main reason for the decreased bandgap. These results suggest the potential application of the material for improved catalytic activity. 

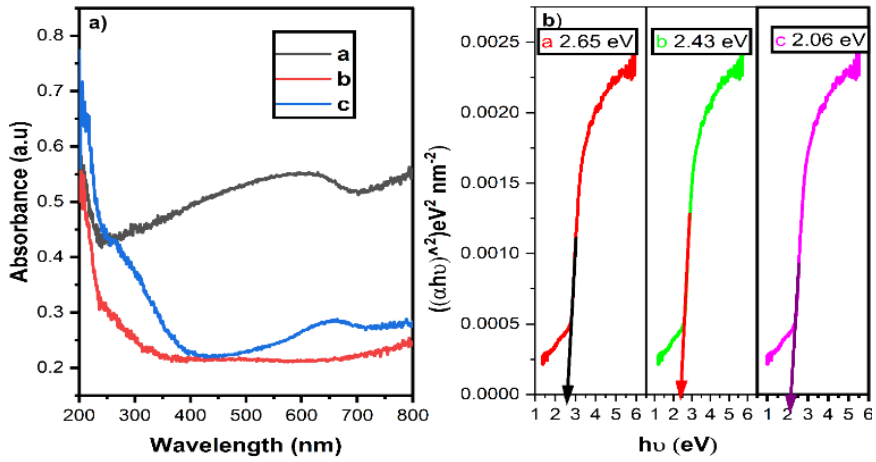

Figure 3. (a) UV/vis DRS spectra of the $\mathrm{Cu}(0.01,0.05$, and $0.1 \mathrm{M})$-doped ZnSe nanoparticles and (b) bandgap spectrum.

\subsection{FE-SEM and EDX Analysis}

The surface morphology and elemental composition of the synthesized $\mathrm{Cu}$-doped ZnSe nanoparticles were evaluated by field emission scanning electron microscope (FESEM) coupled with energy dispersive X-ray analysis (EDX), as shown in Figure 4a-f. The raw $\mathrm{ZnSe}$ nanoparticles have been shown to exhibit a spherical shape [32]. The presence of $\mathrm{Cu}^{2+}$ ions in the $\mathrm{ZnSe}$ surface modifies the shape and size of the $\mathrm{Cu}$-doped $\mathrm{ZnSe}$ nanoparticles (Figure $4 \mathrm{a}-\mathrm{c}$ ). The $\mathrm{Cu}$-doped $\mathrm{ZnSe}$ nanoparticles exhibit a quasi-spherical shape. The modifications in the structure due to the dopant in various concentration (0.01, 0.05 , and $0.1 \mathrm{M}$ of $\mathrm{Cu}^{2+}$ ions) induce a structural and morphological stability. The presence of low-level $\mathrm{Cu}^{2+}$ in the ZnSe nanoparticles shows a mixed spherical shape (Figure 4a,b). The copper-rich ZnSe nanoparticle shows a better quasi-spherical shape than samples a and $b$ (Figure $4 c$ ).
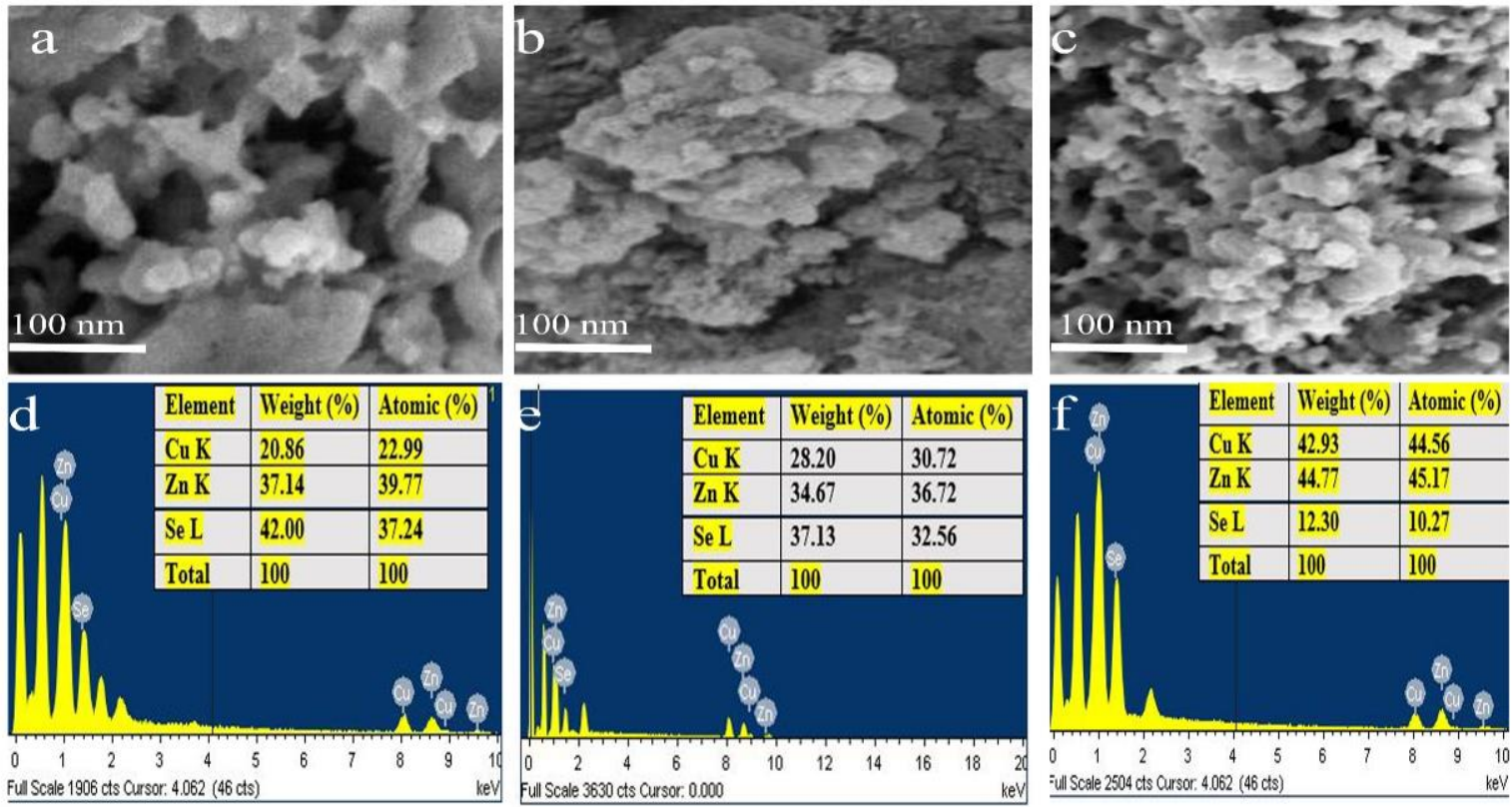

Figure 4. FE-SEM images of $\mathrm{Cu}$ (a) $0.01 \mathrm{M}$ at $100 \mathrm{~nm}$, (b) $0.05 \mathrm{M}$ at $100 \mathrm{~nm}$, and (c) $0.1 \mathrm{M}$ at $100 \mathrm{~nm}$-doped ZnSe nanoparticles and EDX spectrum of $\mathrm{Cu}(\mathbf{d}) 0.01 \mathrm{M}$ at $100 \mathrm{~nm},(\mathbf{e}) 0.05 \mathrm{M}$ at $100 \mathrm{~nm}$, and (f) $0.1 \mathrm{M}$ at $100 \mathrm{~nm}$-doped ZnSe nanoparticles.

The atomic and weight percentages of the elements present in the sample were measured by energy dispersive X-ray analysis (EDX) (Figure $4 \mathrm{~d}-\mathrm{f}$ ). The presence of copper, zinc, and selenium confirms the existence of the respective elemental constituents. The elements and their atomic and weight percentages are tabulated in Figure $4 \mathrm{~d}-\mathrm{f}$ as an inset. 
The different concentration of $\mathrm{Cu}^{2+}$ was listed in the EDX spectrum. The high copper content results in a change in the shape and size of the as synthesized nanoparticles.

\subsection{HR-TEM Analysis}

The synthesized Cu-doped ZnSe nanoparticles represent the HR-TEM image of quasispherical shape in Figure $5 \mathrm{a}, \mathrm{b}$. $\mathrm{Cu}^{2+}$ ions have similar ionic radii to $\mathrm{Zn}^{2+}$ ions in the $\mathrm{Cu}$-doped $\mathrm{ZnSe}$ lattice. Therefore, the $\mathrm{Cu}^{2+}$ ions are expected to be incorporated into the $\mathrm{ZnSe}$ crystal structure. The size of the $\mathrm{Cu}$-doped $\mathrm{ZnSe}$ nanoparticle is $33 \mathrm{~nm}$, which is nearly equal to the crystallite size. The poly crystallite nature of the spherical shape informed the formation of the $\mathrm{Cu}^{2+}$ and $\mathrm{Cu}$ (II) phase in $\mathrm{ZnSe}$ nanoparticles. The raw $\mathrm{ZnSe}$ nanoparticle has been found to exhibit a spherical shape, but the presence of dopant as $\mathrm{Cu}$ reforms the shape into a quasi-spherical shape $[25,34]$.
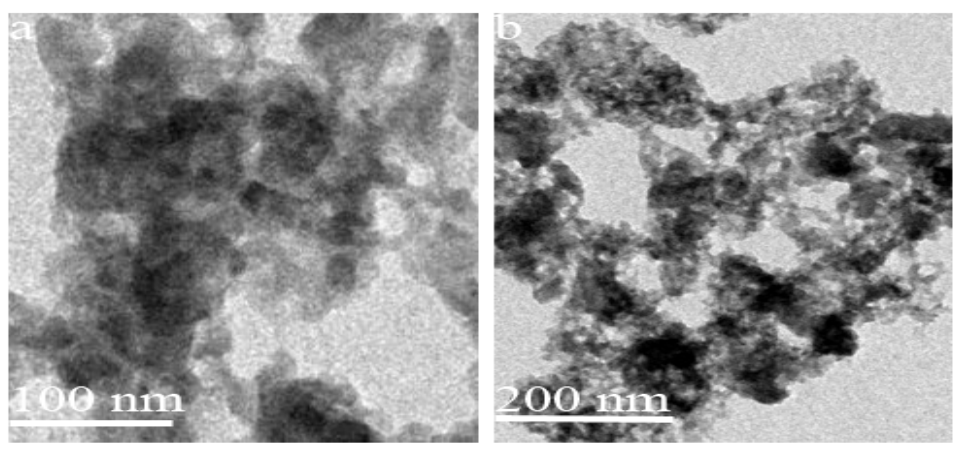

Figure 5. HR-TEM images of Cu (0.1 M)-doped ZnSe nanoparticles (a) $100 \mathrm{~nm}$ (b) $200 \mathrm{~nm}$.

\subsection{XPS Analysis}

The valency and chemical state and bonding between the materials were elucidated by $\mathrm{X}$-ray photoelectron spectroscopy (XPS). Figure 6a-e represent the characteristic spectrum of Cu-doped ZnSe nanoparticles in the survey spectrum (a), Cu-2p spectrum (b), Zn-2p spectrum (C), Se-3d spectrum (d), and C-1s spectrum (e). The Cu 2p3/2 (934.58 eV) and Cu $2 \mathrm{p} 1 / 2(954.58 \mathrm{eV}$ ) (Figure 6a) represent the metallic Cu core with the difference of $20 \mathrm{eV}$ (spin-orbit coupling). The remaining two peaks of the copper spectrum indicate the $\mathrm{Cu}$ $2 \mathrm{p}$ state and represent the existence of the $\mathrm{Cu}^{2+}$ with a binding energy of $942.65 \mathrm{eV}$ and $962.65 \mathrm{eV}$ [35]. The peaks at $1022.23 \mathrm{eV}$ and $1045.48 \mathrm{eV}$ in Figure $6 \mathrm{~b}$ point towards $\mathrm{Zn} 2 \mathrm{p}_{1 / 2}$ and $\mathrm{Zn} 2 \mathrm{p}_{3 / 2}$, respectively (Figure 6c) [36]. The selenium peaks at $59.33 \mathrm{eV}$ and $55.06 \mathrm{eV}$ represent Se-3d $d_{3 / 2}$ and Se $3 d_{5 / 2}$, respectively [37]. The copper state of C-1s represents the existence of $\mathrm{Cu}^{2+}, \mathrm{Zn}^{2+}$, and $\mathrm{Se}^{2-}$ in $285.40 \mathrm{eV}$ (Figure 6e). The metal ions and bonding between them demonstrate the successful preparation of $\mathrm{Cu}$-doped $\mathrm{ZnSe}$ nanoparticles. Copper is widely used for photocatalytic applications thanks to its oxidative tendency. The zinc selenide nanoparticles doped with copper metal result in enhancing the catalytic activity used for degradation of the organic dyes and antibacterial activity.

\subsection{Antibacterial Activity}

The antibacterial activity of $\mathrm{Cu}$-doped $\mathrm{ZnSe}$ nanoparticles was investigated by the dose diffusion method against gram-positive (S. aureus) and gram-negative (E. coli) bacteria. The $\mathrm{Cu}^{2+}$ ions increased the zone of inhibition for the target species as the concentration of $\mathrm{Cu}$-doped $\mathrm{ZnSe}$ nanoparticles increased from $25 \mu \mathrm{L}$ to $100 \mu \mathrm{L}$. The three different concentrations of $\mathrm{Cu}$-doped $\mathrm{ZnSe}$ nanoparticles were used to target the bacterial strains and develop a zone of inhibitions, as shown in Figure 7. The largest zone of inhibition is shown for the highest concentration of $\mathrm{Cu}$. The dissolution rate and release of ions determined the destruction of the strains. Here, the gram-negative bacterial growth was suppressed more than that of gram-positive bacteria. The gram-negative bacteria cell wall is weaker than that of the gram-positive bacteria. Therefore, the $\mathrm{Cu}^{2+}$ ions easily enter 
and constrict the growth of negative bacteria. Thus, the $\mathrm{Cu}$-doped nanoparticles produce efficient antibacterial activity [38].
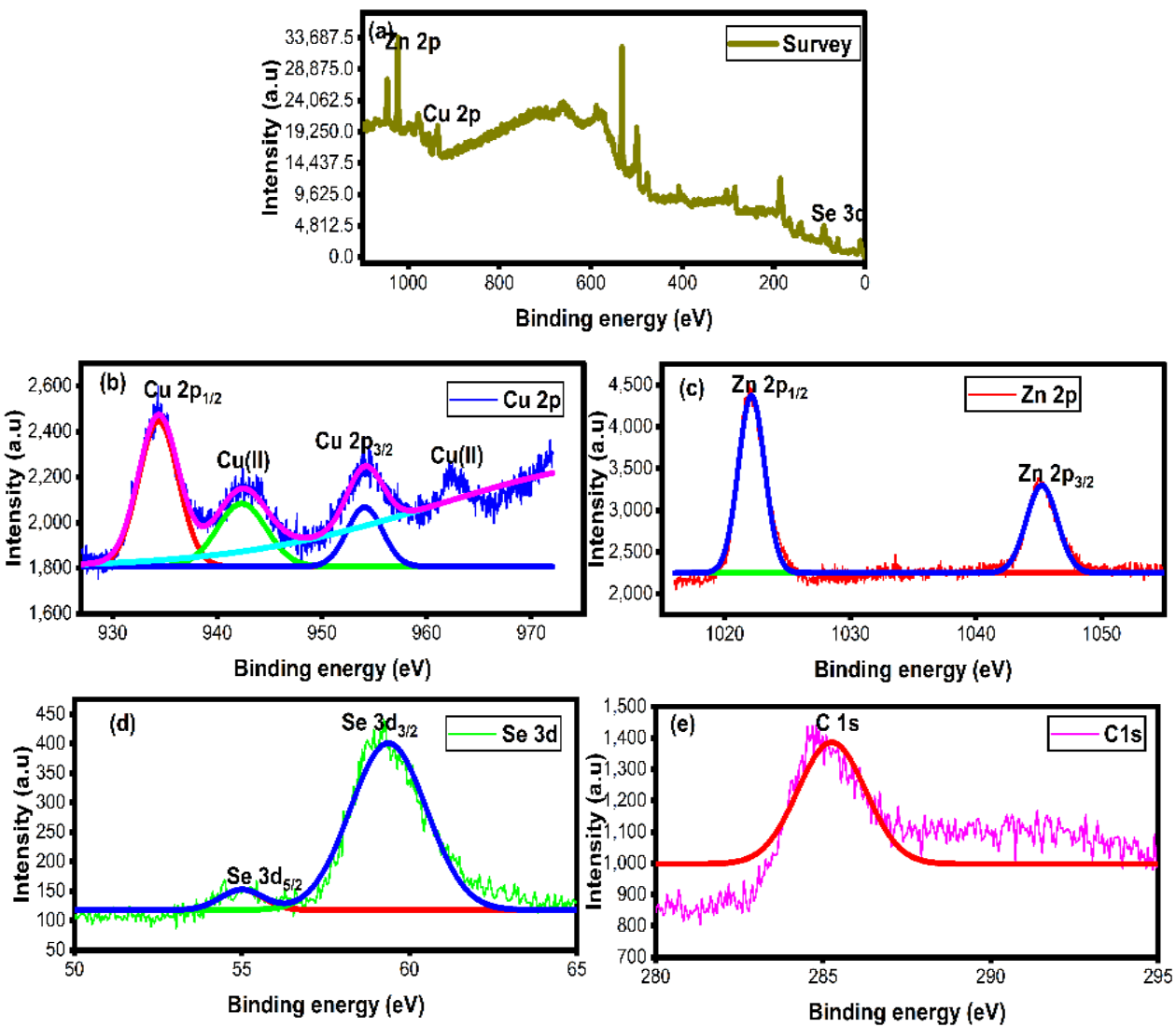

Figure 6. XPS spectra of $\mathrm{Cu} / \mathrm{ZnSe}(0.1 \mathrm{M})$ nanoparticles: (a) wide spectrum, (b) Cu-2p spectrum, (c) Zn 2p spectrum, (d) Se 3d spectrum, and (e) C 1s spectrum.

\section{Antibacterial activity}

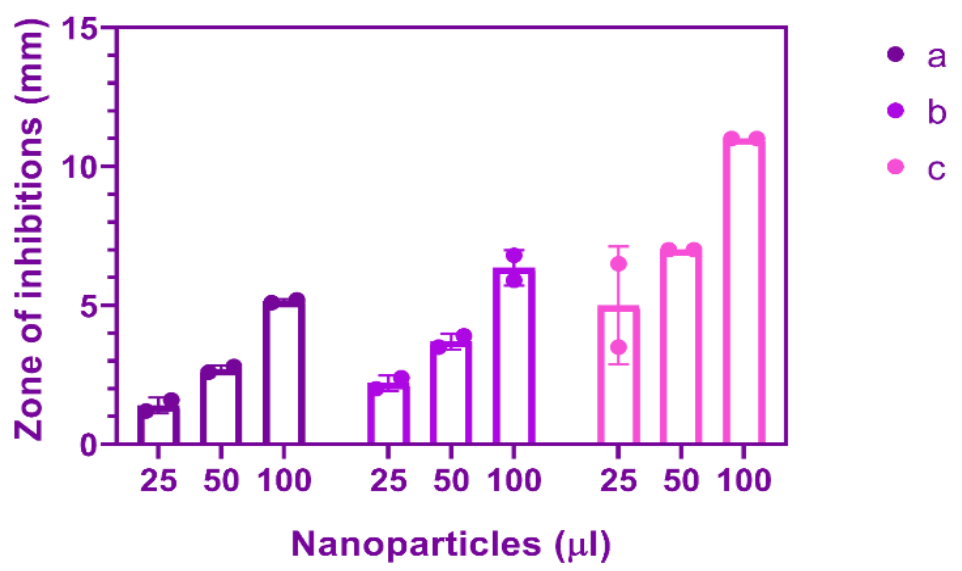

Figure 7. Antibacterial activity of $\mathrm{Cu}$ (a) 0.01 , (b) 0.05 , and (c) $0.1 \mathrm{M}$ doped ZnSe nanoparticles.

\subsection{Mechanism of Antibacterial Activity of Cu-Doped ZnSe Nanoparticles}

The possible mechanism of $\mathrm{Cu}$-doped $\mathrm{ZnSe}$ nanoparticles against bacteria is shown in Figure 8 . The mechanism is based on two important actions, which are 


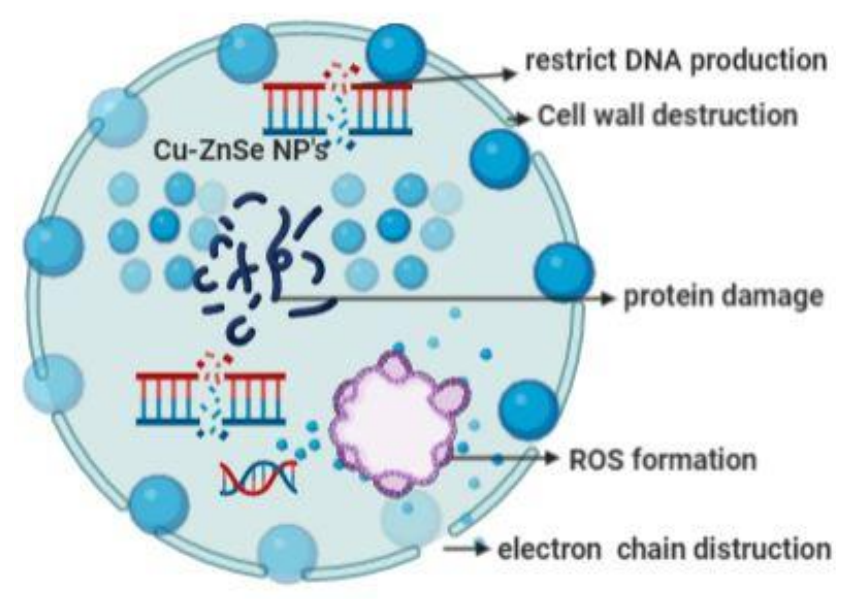

Figure 8. Antibacterial activity mechanism of $\mathrm{Cu} / \mathrm{ZnSe}$ nanoparticles.

- Cell wall destruction;

- ROS formation (reactive oxygen species).

The positively charged nanoparticles target the negatively charged bacteria, interacting by the electrostatic force of attraction. The interaction results in electron chain destruction, restricts DNA production, and damages the protein. The ROS formation may stop the multiplication/production of the bacteria, which leads to cell death [39].

\subsection{Photocatalytic Dye Degradation}

The photocatalytic dye degradation of $\mathrm{Cu}$-doped $\mathrm{ZnSe}$ nanoparticles was examined against the MO dye under a visible light source using a xenon lamp above $400 \mathrm{~nm}$. The degradation spectrum is shown in Figure 9. The MO dye absorbance decreased with the addition of a catalyst and increased time interval. The degradation activity of pristine ZnSe nanoparticles shows a decrease in absorbance by $75 \%$ for $\mathrm{MO}$ in $120 \mathrm{~min}$ [40]. The dye is slowly shown to lose its colour with increasing time. The presence of copper in Cu-doped ZnSe nanoparticles enhances the surface area and induces photo charge carriers to degrade MO dye, as depicted in Figure 10a,b. The \% of photodegradation of the dye is estimated as $78 \%<83 \%<87 \%$ for different concentrations of $\mathrm{Cu}$ in ZnSe nanoparticles The photolysis process without the catalyst shows a meagre value of photodegradation of $\mathrm{MO}$, i.e., $4 \%$. The commercial photocatalyst of P25 as compared with $\mathrm{Cu} / \mathrm{ZnSe}$ nanoparticles reflects a degradation of $96 \%$, which is nearly equal to the $\mathrm{Cu} / \mathrm{ZnSe}$ catalyst at $0.1 \mathrm{M} \mathrm{Cu}$ concentration. The visible light source was irradiated onto the $\mathrm{Cu}$-doped $\mathrm{ZnSe}$ nanoparticles with MO dye in the solution, allowing the electrons to move from a low energy valence band to a high energy conduction band. The charge carriers as electrons and holes render the property of reduction and oxidation in the conduction band and valence band, respectively. The copper metal may improve the surface morphology of ZnSe nanoparticles, which could allow more light penetration to the active sites with a decrease in band gap. The p-type copper-doped ZnSe nanoparticles induce the process of oxidation and reduction process for efficient catalytic activity. The rate of degradation was calculated using the pseudo-first order kinetics and the value of the rate constant is enlisted as follows: $0.01243 \mathrm{~min}^{-1}<$ $0.01300 \mathrm{~min}^{-1}<0.1334 \mathrm{~min}^{-1}$. Sample $\mathrm{c}$ has higher kinetics values than the other samples (Figure 10b), which shows better performance for photodegradation. 


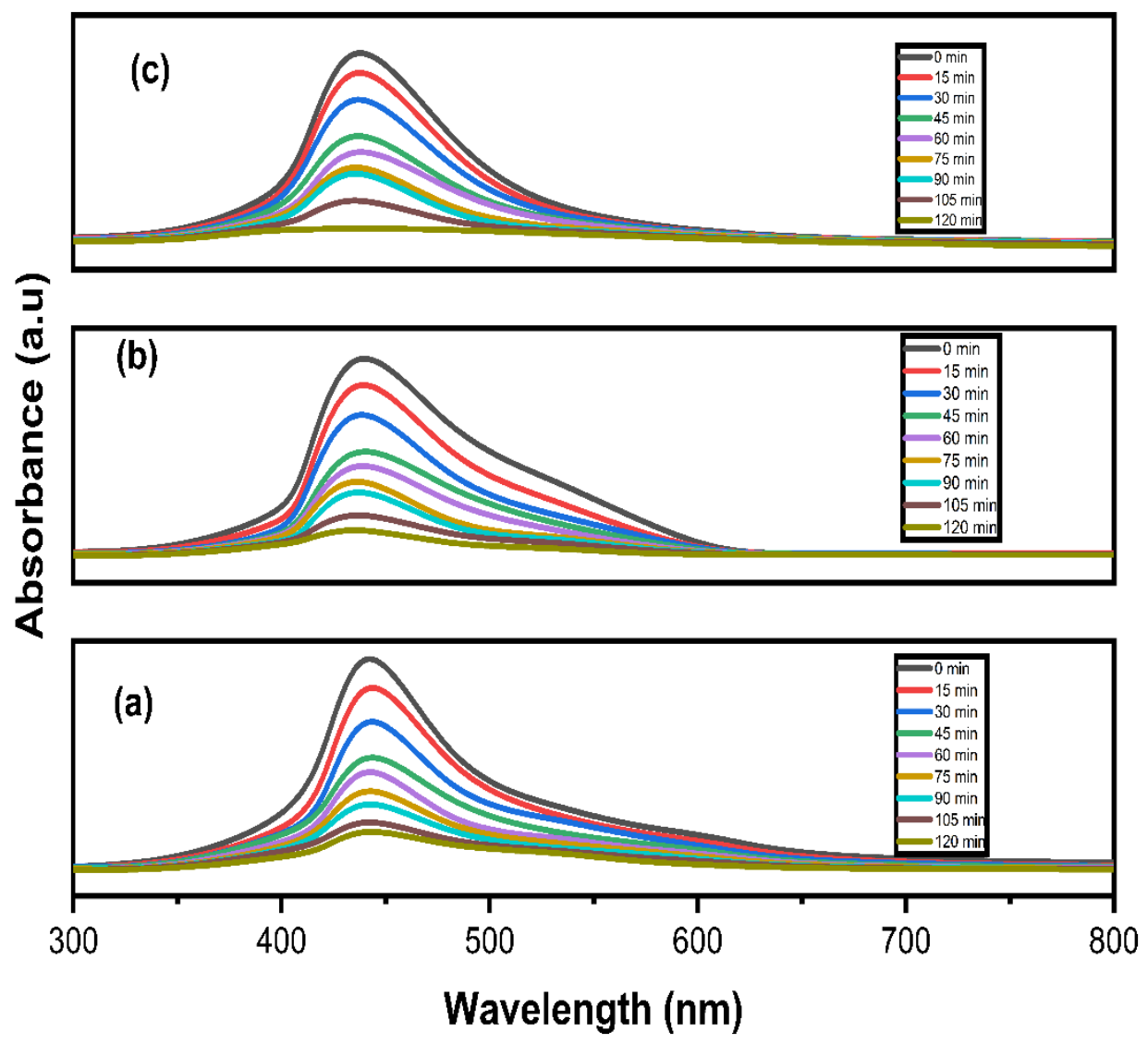

Figure 9. Photocatalyst dye degradation with (a) $0.01 \mathrm{M} \mathrm{Cu}$, (b) $0.05 \mathrm{Cu}$, and (c) $0.1 \mathrm{M} \mathrm{Cu}$ in Cu/ZnSe nanoparticles against MO dye spectrum.

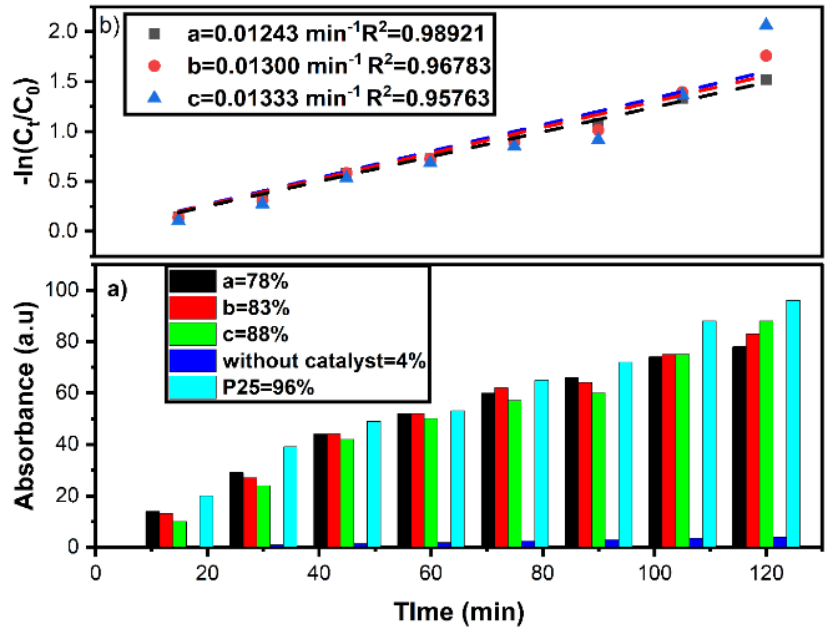

Figure 10. Photocatalytic dye degradation (a) compared with commercial photocatalyst and without catalyst and (b) pseudo-first-order kinetics of the $\mathrm{Cu} / \mathrm{ZnSe}$ nanoparticles with different $\mathrm{Cu}$ concentrations.

\section{Conclusions}

The facile co-precipitation method was used to synthesize Cu-doped ZnSe nanoparticles. The co-precipitation method has been found to be simple, less time- and energyconsuming, sustainable, and economical compared with other conventional methods. The copper integration was carried out on a ZnSe cubic structure. The structural modifications were confirmed by XRD and the average crystallite size was estimated as $31 \mathrm{~nm}$ for $0.1 \mathrm{M}$ 
$\mathrm{Cu}$-doped ZnSe. The phase purity, optical transformations, and valency of the Cu-doped ZnSe nanoparticles revealed the structural modification of the catalyst. Different concentrations of $\mathrm{Cu}$-doped $\mathrm{ZnSe}$ nanoparticles were used to study the catalytic activity. Among them, $0.1 \mathrm{M} \mathrm{Cu}$-doped $\mathrm{ZnSe}$ nanoparticles have exhibited excellent photocatalytic activity towards MO dye. The $0.1 \mathrm{M} \mathrm{Cu}$-doped $\mathrm{ZnSe}$ nanoparticles also exhibit noticeable antibacterial activity against the gram-positive and gram-negative bacteria. This work suggests that the $\mathrm{Cu}$-doped $\mathrm{ZnSe}$ nanoparticles portray a prominent photocatalytic and antibacterial activity. Hence, the synthesized $\mathrm{Cu}$-doped $\mathrm{ZnSe}$ nanoparticles can be used for developing a large-scale wastewater purification system for the degradation of contaminates.

Author Contributions: Conceptualization, V.B. and S.L.R.; methodology, A.A.; software, V.B.; validation, K.M.A., T.S.A. and M.O.; formal analysis, S.A. (S. Ajitha); investigation, F.J.I.; resources, M.O.; data curation, M.O.; writing—original draft preparation, A.A.; writing—review and editing, F.J.I.; visualization, V.B.; supervision, S.A. (Shafaqat Ali); project administration, S.A. (Shafaqat Ali); funding acquisition, T.S.A. All authors have read and agreed to the published version of the manuscript.

Funding: The authors appreciated Taif University Researchers Supporting Project number TURSP2020/267, Taif University, Taif, Saudi Arabia. This research was funded by the Deanship of Scientific Research at Princess Nourah bint Abdulrahman University through the Fast-track Research Funding Program.

Institutional Review Board Statement: Not applicable.

Informed Consent Statement: Not applicable.

Data Availability Statement: Not applicable.

Conflicts of Interest: The authors declare no conflict of interest.

\section{References}

1. Julkapli, N.M.; Bagheri, S.; Bee Abd Hamid, S. Recent Advances in Heterogeneous Photocatalytic Decolorization of Synthetic Dyes. Sci. World J. 2014, 2014, 692307. [CrossRef] [PubMed]

2. Bibi, S.; Ahmad, A.; Anjum, M.A.R.; Haleem, A.; Siddiq, M.; Shah, S.S.; Al Kahtani, A. Photocatalytic degradation of malachite green and methylene blue over reduced graphene oxide $(\mathrm{rGO})$ based metal oxides $\left(\mathrm{rGO}-\mathrm{Fe}_{3} \mathrm{O}_{4} / \mathrm{TiO}_{2}\right)$ nanocomposite under UV-visible light irradiation. J. Environ. Chem. Eng. 2021, 9, 105580. [CrossRef]

3. Ahmad, I.; Jamal, M.A.; Iftikhar, M.; Ahmad, A.; Hussain, S.; Asghar, H.; Saeed, M.; Yousaf, A.B.; Karri, R.R.; Al-kadhi, N.S.; et al. Lanthanum-Zinc Binary Oxide Nanocomposite with Promising Heterogeneous Catalysis Performance for the Active Conversion of 4-Nitrophenol into 4-Aminophenol. Coatings 2021, 11, 537. [CrossRef]

4. Kashif, M.; Jafaar, E.; Sahari, S.K.; Low, F.W.; Hoa, N.D.; Ahmad, A.; Abbas, A.; Ngaini, Z.; Shafa, M.; Qurashi, A. Organic sensitization of graphene oxide and reduced graphene oxide thin films for photovoltaic applications. Int. J. Energy Res. 2021, 45, 9657-9666. [CrossRef]

5. Saleem, M.; Irfan, M.; Tabassum, S.; Albaqami, M.D.; Javed, M.S.; Hussain, S.; Pervaiz, M.; Ahmad, I.; Ahmad, A.; Zuber, M. Experimental and theoretical study of highly porous lignocellulose assisted metal oxide photoelectrodes for dye-sensitized solar cells. Arab. J. Chem. 2021, 14, 102937. [CrossRef]

6. Aravind, M.; Ahmad, A.; Ahmad, I.; Amalanathan, M.; Naseem, K.; Mary, S.M.M.; Parvathiraja, C.; Hussain, S.; Algarni, T.S.; Zuber, M.P.M. Critical green routing synthesis of silver NPs using jasmine flower extract for biological activities and photocatalytical degradation of methylene blue. J. Environ. Chem. Eng. 2021, 9, 104877. [CrossRef]

7. Hussain, S.; Khan, A.J.; Arshad, M.; Javed, M.S.; Ahmad, A.; Shah, S.S.A.; Khan, M.R.; Akram, S.; Zulfiqar; Ali, S.; et al. Charge storage in binder-free 2D-hexagonal $\mathrm{CoMoO}_{4}$ nanosheets as a redox active material for pseudocapacitors. Ceram. Int. 2021, 47, 8659-8667. [CrossRef]

8. Beena, V.; Rayar, S.L.; Ajitha, S.; Ahmad, A.; Albaqami, M.D.; Alsabar, F.A.A.; Sillanpää, M. Synthesis and Characterization of Sr-Doped ZnSe Nanoparticles for Catalytic and Biological Activities. Water 2021, 13, 2189. [CrossRef]

9. Ahmad, A.; Jini, D.; Aravind, M.; Parvathiraja, C.; Ali, R.; Kiyani, M.Z.; Alothman, A. A novel study on synthesis of egg shell based activated carbon for degradation of methylene blue via photocatalysis. Arab. J. Chem. 2020, 13, 8717-8722. [CrossRef]

10. Vaez, Z.; Javanbakht, V. Synthesis, characterization and photocatalytic activity of ZSM-5/ZnO nanocomposite modified by Ag nanoparticles for methyl orange degradation. J. Photochem. Photobiol. A Chem. 2020, 388, 112064. [CrossRef]

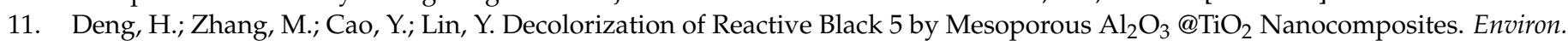
Prog. Sustain. Energy 2019, 38, S230-S242. [CrossRef]

12. Rajendran, S.; Khan, M.M.; Gracia, F.; Qin, J.; Gupta, V.K.; Arumainathan, S. Ce ${ }^{3+}$-ion-induced visible-light photocatalytic degradation and electrochemical activity of $\mathrm{ZnO} / \mathrm{CeO}_{2}$ nanocomposite. Sci. Rep. 2016, 6, 31641. [CrossRef] 
13. Shaikh, A.F.; Arbuj, S.S.; Tamboli, M.S.; Naik, S.D.; Rane, S.B.; Kale, B.B. ZnSe/ZnO nano-heterostructures for enhanced solar light hydrogen generation. ChemistrySelect 2017, 2, 9174-9180. [CrossRef]

14. Mkhalid, I.A. Improved photocatalytic performance in Bi2S3-ZnSe nanocomposites for hydrogen production. Ceram. Int. 2018, 44, 22198-22204. [CrossRef]

15. Ehsan, M.F.; Bashir, S.; Hamid, S.; Zia, A.; Abbas, Y.; Umbreen, K.; Ashiq, M.N.; Shah, A. One-pot facile synthesis of the ZnO/ZnSe heterostructures for efficient photocatalytic degradation of azo dye. Appl. Surf. Sci. 2018, 459, 194-200. [CrossRef]

16. Zhang, J.; Tian, P.; Tang, T.; Huang, G.; Zeng, J.; Cui, B.; Shen, Z.; Wang, H.; Kong, Z.; Xi, J.; et al. Excellent photoelectrochemical hydrogen evolution performance of $\mathrm{FeSe} 2$ nanorod/ZnSe 0D/1D heterostructure as efficiency carriers migrate channel. Int. J. Hydrogen Energy 2020, 45, 8526-8539. [CrossRef]

17. Sanchez-Martinez, A.; Ortiz-Beas, J.P.; Huerta-Flores, A.M.; López-Mena, E.R.; Pérez-Álvarez, J.; Ceballos-Sanchez, O. ZnSe nanoparticles prepared by coprecipitation method for photocatalytic applications. Mater. Lett. 2021, 282, 128702. [CrossRef]

18. Hao, E.; Zhang, H.; Yang, B.; Ren, H.; Shen, J. Preparation of Luminescent Polyelectrolyte/Cu-Doped ZnSe Nanoparticle Multilayer Composite Films. J. Colloid Interface Sci. 2001, 238, 285-290. [CrossRef] [PubMed]

19. Ummartyotin, S.; Bunnak, N.; Juntaro, J.; Sain, M.; Manuspiya, H. Synthesis and luminescence properties of ZnS and metal (Mn, Cu)-doped-ZnS ceramic powder. Solid State Sci. 2014, 14, 299-304. [CrossRef]

20. Srivastava, R.K.; Pandey, N.; Mishra, S.K. Effect of Cu concentration on the photoconductivity properties of ZnS nanoparticles synthesized by co-precipitation method. Mater. Sci. Semicond. Process. 2013, 16, 1659-1664. [CrossRef]

21. Modwi, A.; Taha, K.K.; Khezami, L.; Boudina, M.; Khairy, M.; Al-Duaij, O.K.; Talab, S. Dependence of the electrical properties of Cu-doped $\mathrm{ZnO}$ nanoparticles decorated by Ag atoms. Z. Phys. Chem. 2021, 235, 745-767. [CrossRef]

22. Mittal, M.; Sharma, M.; Pandey, O.P. UV-Visible light induced photocatalytic studies of Cu doped ZnO nanoparticles prepared by co-precipitation method. Sol. Energy 2014, 110, 386-397. [CrossRef]

23. Chauhan, R.; Kumar, A.; Chaudhary, R.P. Photocatalytic degradation of methylene blue with Cu doped ZnS nanoparticles. J. Lumin. 2014, 145, 6-12. [CrossRef]

24. Senda, S.; Arai, T.; Sato, Y.; Shinoda, K.; Jeyadevan, B.; Tohji, K. Influence of $\mathrm{Cu}$ on the photocatalytic activity of ZnS nanoparticles. AIP Conf. Proc. 2006, 833, 65. [CrossRef]

25. Beena, V.; Ajitha, S.; Rayar, L.S.; Parvathiraja, C.; Kannan, K.; Palani, G. Enhanced Photocatalytic and Antibacterial Activities of ZnSe Nanoparticles. J. Inorg. Organomet. Polym. Mater. 2021, 6, 1-12.

26. Bezverkhyy, I.; Skrzypski, J.; Safonova, O.; Bellat, J.P. Sulfidation mechanism of pure and Cu-doped ZnO nanoparticles at moderate temperature: TEM and in situ XRD studies. J. Phys. Chem. C 2012, 116, 14423-14430. [CrossRef]

27. Hao, H.; Yao, X.; Wang, M. Preparation and optical characteristics of ZnSe nanocrystals doped glass by sol-gel in situ crystallization method. Opt. Mater. 2007, 29, 573-577. [CrossRef]

28. Eren, E.; Afsin, B. An investigation of $\mathrm{Cu}$ (II) adsorption by raw and acid-activated bentonite: A combined potentiometric, thermodynamic, XRD, IR, DTA study. J. Hazard. Mater. 2008, 151, 682-691. [CrossRef]

29. Chen, R.; Guo, C.; Chu, W.; Jiang, N.; Li, H. ATR-FTIR study of Bacillus sp. and Escherichia coli settlements on the bare and $\mathrm{Al}_{2} \mathrm{O}_{3}$ coated $\mathrm{ZnSe}$ internal reflection element. Chin. Chem. Lett. 2019, 30, 115-119. [CrossRef]

30. Majumdar, S.S.; Das, S.K.; Saha, T.; Panda, G.C.; Bandyopadhyoy, T.; Guha, A.K. Adsorption behavior of copper ions on Mucor rouxii biomass through microscopic and FTIR analysis. Colloids Surf. B Biointerfaces 2008, 63, 138-145. [CrossRef]

31. Hines, M.A.; Guyot-Sionnest, P. Bright UV-blue luminescent colloidal ZnSe nanocrystals. J. Phys. Chem. B. 1998, 102, 3655-3657. [CrossRef]

32. Giordanino, F.; Vennestrøm, P.N.; Lundegaard, L.F.; Stappen, F.N.; Mossin, S.; Beato, P.; Bordiga, S.; Lamberti, C. Characterization of Cu-exchanged SSZ-13: A comparative FTIR, UV-Vis, and EPR study with Cu-ZSM-5 and Cu- $\beta$ with similar Si/Al and Cu/Al ratios. Dalton Trans. 2013, 42, 12741-12761. [CrossRef]

33. Mallem, S.P.R.; Koduru, M.; Chandrasekhar, K.; Prabhakar Vattikuti, S.V.; Manne, R.; Reddy, V.R.; Lee, J.H. Potato Chip-Like Od Interconnected Znco2o4 Nanoparticles High-Perform. Supercapacitors. Crystals 2021, 11, 469. [CrossRef]

34. Shakir, M.; Kushwaha, S.K.; Maurya, K.K.; Bhagavannarayana, G.; Wahab, M.A. Characterization of ZnSe nanoparticles synthesized by microwave heating process. Solid State Commun. 2009, 149, 2047-2049. [CrossRef]

35. Liang, Q.; Bai, Y.; Han, L.; Deng, X.; Wu, X.; Wang, Z.; Liu, X.; Meng, J. Hydrothermal synthesis of ZnSe: Cu quantum dots and their luminescent mechanism study by first-principles. J. Lumin. 2013, 143, 185-192. [CrossRef]

36. Ghodselahi, T.; Vesaghi, M.A.; Shafiekhani, A.; Baghizadeh, A.; Lameii, M. XPS study of the Cu@ Cu글 $\mathrm{O}$ core-shell nanoparticles Appl. Surf. Sci. 2008, 255, 2730-2734. [CrossRef]

37. Feliu, S., Jr.; Barranco, V.X.P.S. XPS study of the surface chemistry of conventional hot-dip galvanised pure Zn, galvanneal and $\mathrm{Zn}-\mathrm{Al}$ alloy coatings on steel. Acta Mater. 2003, 51, 5413-5424. [CrossRef]

38. Agostinelli, E.; Battistoni, C.; Fiorani, D.; Mattogno, G.; Nogues, M. An XPS study of the electronic structure of the ZnxCd1xCr2 (X = S, Se) spinel system. J. Phys. Chem. Solids 1989, 50, 269-272. [CrossRef]

39. Nigussie, G.Y.; Tesfamariam, G.M.; Tegegne, B.M.; Weldemichel, Y.A.; Gebreab, T.W.; Gebrehiwot, D.G.; Gebremichel, G.E. Antibacterial activity of Ag-doped $\mathrm{TiO}_{2}$ and Ag-doped $\mathrm{ZnO}$ nanoparticles. Int. J. Photoenergy 2018, 2018, 5927485. [CrossRef]

40. Chaliha, C.; Nath, B.K.; Verma, P.K.; Kalita, E. Synthesis of functionalized Cu: ZnS nanosystems and its antibacterial potential. Arab. J. Chem. 2019, 12, 515-524. [CrossRef] 